\title{
OSTEOARTHRITIS AND MORTALITY: A PROSPECTIVE COHORT STUDY AND SYSTEMATIC REVIEW WITH META-ANALYSIS
}

Nicola Veronese ${ }^{1 *}$, Emanuele Cereda ${ }^{2 *}$, Stefania Maggi ${ }^{3}$, Claudio Luchini ${ }^{4}$, Marco Solmi ${ }^{5,6}$, Toby Smith $^{7}$, Michael Denkinger ${ }^{8,9}$ Michael Hurley ${ }^{10}$, Trevor Thompson ${ }^{11}$, Enzo Manzato ${ }^{1,3}$, Giuseppe Sergi $^{1}$, Brendon Stubbs ${ }^{12,13}$

\footnotetext{
${ }^{1}$ University of Padova, Department of Medicine (DIMED), Geriatrics Section, Padova, Italy.

${ }^{2}$ Nutrition and Dietetics Service, Fondazione IRCCS Policlinico San Matteo, Pavia, Italy.

${ }^{3}$ Institute of Neuroscience, Aging Branch, National Research Council-CNR, Padova, Italy.

${ }^{4}$ Department of Pathology and Diagnostics, University and Hospital Trust of Verona, Verona.

${ }^{5}$ Department of Neurosciences, University of Padova, Padova, Italy.

${ }^{6}$ Local Health Unit 17, Mental Health Department, Padova, Italy

${ }^{7}$ Faculty of Medicine and Health Sciences, School of Health Sciences, Queen's Building, University of East Anglia, Norwich Research Park, Norwich, NR4 7TJ, United Kingdom.

${ }^{8}$ AGAPLESION Bethesda Clinic, Geriatric Research Unit, University of Ulm, Ulm, Germany

${ }^{9}$ Geriatric Centre Ulm/Alb-Donau, Ulm University, Ulm, Germany

${ }^{10}$ St Georges University of London, Faculty of Health and Social Care Sciences, London, United Kingdom.

${ }^{11}$ Faculty of Education and Health, University of Greenwich, London, United Kingdom.

${ }^{12}$ Health Service and Population Research Department, Institute of Psychiatry, King's College London, De Crespigny Park, London, Box SE5 8AF, United Kingdom.

${ }^{13}$ Physiotherapy Department, South London and Maudsley NHS Foundation Trust, Denmark Hill, London, SE5 8AZ, United Kingdom.
}

* These Authors equally contributed to this research.

Corresponding Author:

Nicola Veronese, MD

University of Padova, Department of Medicine (DIMED)-Geriatrics Section,

Via Giustiniani, 2

35128 Padova, Italy.

E-mail: ilmannato@gmail.com

Word count: 3863 


\section{ABSTRACT}

Objectives: Osteoarthritis (OA) is a leading cause of disability, but the relationship with premature mortality remains uncertain. We aimed to investigate the relationship between OA and mortality from any cause and from cardiovascular disease (CVD). searches were conducted to identify prospective studies comparing mortality in a sample of people with and without OA. Risk of all-cause and CVD mortality were summarized using adjusted hazard ratios (HRs) for joint specific (hand, hip, and knee) and joint non-specific OA. New data from the Progetto Veneto Anziani (PRO.V.A.) study were also included. Results: From the PRO.V.A. study (N 1/4 2927), there was no significant increase in mortality risk for participants with any joint OA (N 1/4 1858) compared to non-OA (all-cause, HR 1/4 0.95, 95\% CI: 0.77-1.15 and CVD, HR 1/4 1.12, 95\% CI: 0.82-1.54). On meta-analysis, seven studies (OA 1/4 10,018/non-OA 1/4 18,541), with a median 12-year follow-up, reported no increased risk of any-cause mortality in those with OA (HR 1/4 1.10, 95\% CI: 0.97-1.25). After removing data on hand OA, a significant association between OA and mortality was observed (HR 1/4 1.18, 95\% CI: 1.08-1.28). There was a significant higher risk of overall mortality for (1) studies conducted in Europe, (2) patients with multi-joint $\mathrm{OA}$; and (3) a radiological diagnosis of OA. OA was associated with significantly higher CVD mortality (HR 1/4 1.21, 95\% CI: 1.10-1.34).

Conclusions: People with OA are at increased risk of death due to CVD. The relationship with overall mortality is less clear and may be moderated by the presence of hand OA.

\section{INTRODUCTION}

Osteoarthritis (OA) is a leading cause of years lived with disability worldwide [1,2]. The leading symptom associated with OA is chronic musculoskeletal pain, which is associated with mobility and function [3,4]. Physical inactivity is independently associated with an increased risk of cardiovascular diseases (CVD) and mortality in the general population [5]. Obesity is also commonly seen within the osteoarthritis population, while also being associated with morbidities such as type two diabetes, cancers, and CVD [6].

CVD are a leading cause of global mortality, with recent estimates demonstrating that CVD account for 17.3 million deaths globally [7]. A recent meta-analysis demonstrated that people with OA are at increased risk of CVDs [8], which may also be influenced by an elevated chronic inflammatory status in some subgroups with OA [9]. Death due to CVD is potentially prevent- able through appropriate timely pharmacological and nonpharmacological interventions [10]. Therefore, to identify people at higher risk of CVD mortality could be of considerable public health importance.

Within the past decade, a number of observational studies have reported that people with OA are at increased risk of premature mortality compared to the general population [11-13]. However, this evidence is heterogeneous and 
limited by the lack of adjust- ment for appropriate confounders.

Given this, the purpose of this study was to (i) analyze data from a prospective cohort study on the risk of CVD mortality in OA compared to a non-osteoarthritis cohort, adjusting for important medical morbidities and other confounders; (ii) to systematically review the available literature and perform a meta-analysis to determine whether people with OA present a differential risk of overall and CVD mortality than those without OA. We hypothe- sized that people with OA had a significant higher risk of overall and CVD death compared to those without OA.

\section{MATERIALS AND METHODS}

\section{Prospective cohort study}

\section{Overall cohort}

Previously unpublished data from the Progetto Veneto Anziani (PRO.V.A. study) were used to investigate the risk of overall and CVD mortality in people with OA over a mean follow-up of 4.4 years. The Pro.V.A. study is an observational cohort study on the Italian population aged over 65 years. The study population initially included 3099 older Caucasian adults (1245 men/1854 women), who were randomly selected between 1995 and 1997 using a multistage stratified method, in two North Italian towns (Camposampiero and Rovigo). Additional details about the study design have been previously reported [14].

\section{Participant selection}

After excluding 172 participants without information about OA, data from 2927 participants (men 1/4 1179/women 1/4 1748) were gathered. Hand, hip, and knee OA presence was assessed through medical history and records, previous x-ray reports, and clinical evaluation. This latter evaluation included for the hand the presence of Heberden nodes, stiffness, and pain at passive moment; for the knee- deformity, pain at passive movement, reduced passive mobility, and crepitus; for the hip—pain at passive movement, rotation and palpation, and reduced external rotation. The diagnosis of OA was finally confirmed by a rheumatologist using a standardized algorithm [15]. Mortality was ascertained through direct reviewing of single death certif- icate, and the main cause of death was recorded using the ICD-9. Death for CVD reasons was defined using the ICD-9 codes from 390 to 459.

\section{Statistical analysis}

Owing to the small number of death attributed to non-CVD, it was not possible to appropriate analyses overall mortality, over CVD mortality from this dataset. Accordingly, the risk of CVD mortality associated with OA was investigated using multivariate 
Cox's regression analysis adjusted for known clinical factors associated with mortality. These included age (continuous); gen- der; body mass index (continuous); educational level ( r 5 vs. 45 years); alcohol drinking (yes vs. no); monthly income ( Z 500 vs. o $500 €$ ); physical activity level ( Z 4 vs. o 4 h/week); presence at baseline of CVD, fractures, chronic obstructive pulmonary disease, orthostatic hypotension (difference in systolic of 20 mmHg or diastolic of 10mmHg between orthostatism and clinostatism) [16], hypertension (use of antihypertensive medications, mean of systolic blood pressure Z140, or mean diastolic blood pressure Z $90 \mathrm{mmHg}$ ) [17], diabetes (fasting plasma glucose Z $126 \mathrm{mg} / \mathrm{dl}$, glycosilated hemoglobin Z7\% or use of anti-diabetic medications) [18], frailty (according with a modified Fried's index) [19], and cancer (all yes vs. no); number of medications (continuous); smoking status (current/former vs. never); and activities of daily living assessed (ADLs) [20], Mini-Mental State Examination (MMSE) [21], Geriatric Depression Scale [22], and Geriatric Nutrition Risk Index scores (GNRI) [23] (all as continuous). For all the scores, with exception of GDS, the higher the score the better the status. In the multivariate analysis, data were missing for 258 ( $1 / 48.8 \%$ ) of the participants, mainly for information about ortho- static hypotension (n 1/4 142), glycosilated hemoglobin (n 1/4 244), and MMSE (n 1/4 125).

Risk estimates were computed for any joint and anatomical region affected (hand, hip, or knee). All analyses were performed using the SPSS 21.0 for Windows (SPSS Inc., Chicago, IL). Statistical significance was assumed for a two-tailed p o 0.05 .

\section{Systematic review}

This systematic review was conducted following the MOOSE (meta-analysis of observational studies in epidemiology) guide- lines and data reporting was performed in agreement with the PRISMA (Preferred Reporting Items for Systematic Reviews and Meta-Analyses) guidelines [24,25].

\section{Data sources and literature search strategy}

We created search strategies for the concepts of "osteoarthritis" and "mortality” using a combination of standardized terms and keywords harvested from indices, thesauri, and on-topic articles (Supplementary Table 1). The electronic databases [PubMed, Embase, Scopus, CiNAHL (via Ebsco), ASSIA (via Proquest), and Social Work Abstracts (via Ebsco)], were search from database inception to November 17, 2015. We further conducted a manual search of reference lists of included and other relevant articles. Authors were contacted in case of lacking information. All articles were reviewed for inclusion by two independent reviewers (N.V. and B.S.). Any discrepancies were resolved by consensus with a third reviewer (E.M.).

\section{Study selection}

Prospective, observational cohort studies were eligible for inclusion if they reported data on OA diagnosed with clinical and/or radiological assessment; reported mortality risk estimates [hazard ratios (HRs)] along with their 95\% CI; and included a control group without OA. Intervention studies and studies includ- ing only participants with joint replacement (e.g., total hip or total knee arthroplasty) were excluded. 


\section{Data extraction}

Overall and CVD risk estimates (adjusted for the maximum number of confounders available) comparing people with OA against people without OA were gathered. One investigator (N.V.) extracted data from the included articles and two independent investigators (C.L. and E.C.) verified these data. For each article we also extracted data about authors, publication year, study location, setting, and participant characteristics by presence of OA [e.g., age, percentage of women, CVD, body mass index (BMI)], follow-up duration (in years), number, and list of covariates used in statistical analyses. Study authors were contacted if necessary.

\section{Outcomes}

The primary outcome included overall mortality in OA com- pared to non-OA participants. Secondary outcomes included over- all mortality based on anatomical site of OA (i.e., hand, hip, and knee) and CVD mortality.

\section{Assessment of study quality}

The Newcastle-Ottawa Scale (NOS) [26] was used to evaluate study quality. The NOS assigns a maximum of nine points to studies of highest quality according to the following three quality parameters: selection (four points), comparability (two points), and outcome (three points). Each included study was assessed by three reviewers. If discrepancies arose in appraisal, these were addressed by a joint re-evaluation of the article (M.S., S.M., and T.S.).

\section{Data synthesis and statistical analysis}

To compensate for potential between study heterogeneity, we calculated a pooled HR using DerSimonian-Laird random-effect model [27]. Statistical heterogeneity across studies was assessed using the Cochrane $\mathrm{I}^{2}$ metric and chi-square statistics [28]. Since the diagnostic criteria for OA involve clinical and radiological parameters [29-31] and evidence has suggested that radiological findings may poorly correlate to clinical presentation [32], in absence of universally agreed recommendations we initially (pri- mary analyses) pooled HRs of overall mortality as provided by the studies regardless of method of diagnosis. Joint specific estimates for overall mortality and CVD-specific death were computed. Within-study pooled estimates were also calculated as necessary (e.g., only joint-specific HRs provided).

Given significant statistical heterogeneity ( $\mathrm{I}^{2} \mathrm{Z}$ 50\%) [33], we conducted meta-regression analyses investigating the following moderators: continent (Europe vs. others), type of diagnosis of OA (clinical vs. radiological vs. combined); follow-up duration, NOS score, number of adjustments (all by median value), death ascer- tainment (using death certificates or other tools), and number of sites affected.

Publication bias was assessed by visually inspecting funnel plots and using the Begg and Mazumdar's Kendall tau [34] and the Egger's bias test [35]. To account for potential publication bias, we used a "trim-and-fill” method, based on the assumption that the effect sizes of all the studies are normally distributed around the center of a funnel plot. In the event of asymmetries, this procedure adjusts for the potential effect of unpublished (imputed) 
studies [36]. All analyses were performed using Comprehensive Meta-Analysis 3.

\section{Results}

Prospective cohort study

Baseline characteristics In the PRO.V.A. study, participants with OA (N 1/4 1858; 63.5\%)

were significantly older, with a greater proportion of women compared to those without OA (n 1/4 1069) (Table 1). Subjects with OA had also a significantly higher presence of potential risk factors for early mortality; including lower GNRI, preserved number of ADLs, and higher presence of depressive symptoms; frailty, osteoporotic fractures, orthostatic hypotension and hypertension, dia- betes, and CVD, compared to the non-OA group (Table 1).

\section{Follow-up and CVD mortality}

Over the 4.4 years of follow-up, 745 participants (men 1/4 380/ women 1/4 365) died. Using Cox's regression analysis and taking participants with no OA for reference, no significant increased risk of death in people with OA emerged [HR 1/4 0.95 (95\% CI: 0.77-1.15); p 1/4 0.58] (Table 2). On the multivariate analysis (Supplementary Table 2), the significant predictors of death were diabetes [HR 1/4 1.50 (95\% CI: 1.20-1.88); p o 0.001], CVD [HR 1/4 1.50 (95\% CI: 1.23-1.82); p o 0.001], COPD [HR 1/4 1.34 (95\% CI: 1.04-1.72); p 1/4 0.03], cancer [HR 1/4 1.37 (95\% CI: 1.03-1.81); p 1/4 0.03], and frailty [HR 1/4 2.12 (95\% CI: 1.52-2.97); p o 0.001]. Higher MMSE and GNRI were protective for mortality [HR 1/4 0.96 (95\% CI: 0.94-0.98); p o 0.001 and HR 1/4 0.96 (95\% CI: 0.95-0.97); p o 0.001, respectively]. A similar lack of association was also found when individually analyzing OA by anatomical site (hand, hip, or knee) or when lower limbs OA was analyzed [HR 1/4 0.97 (95\% CI: 0.82-1.14); p 1/4 0.48]. Finally, OA did not significantly increase the risk of CVD death [total number of events, n 1/4 373; HR 1/4 1.12 (95\% CI: 0.83-1.55); p 1/4 0.53]. Other causes of death could not be investigated (respiratory, n 1/4 128; cancer, n 1/4 58; and others 1/4 186).

\section{Systematic review}

\section{Search results}

In total, 2139 non-duplicated articles were identified. After excluding 2124 articles based on title/abstract review, 15 articles were fully retrieved and six were included [37-42] along with data from the PRO.V.A study (Supplementary Fig.). For one conference abstract [38], additional data were gathered from the authors.

\section{Study and population characteristics}

As reported in Table 3, the seven meta-analyzed studies followed 28,559 participants (OA 1/4 10,018/non-OA 1/4 18,541) for a median duration of 12 (IQR: 6.5-18) years. Participants were all community dwellers, mainly European (N 1/4 4; 57\%). The assess- ment of OA was heterogeneous across studies with two [37,38] and five (PRO.V.A and [39-42]) reporting a radiological and a combined (clinical p radiological) assessment, respectively. 
Differ- ent methods of death ascertainment were also observed, but six out of seven were of high reliability and quality [37-41]. Finally, four of the included studies also provided data for CVD mortality (PRO.V.A and $[37,38,41])$.

\section{Quality assessment}

The median NOS score was seven (IQR: 6-8). The most common source of bias was the ascertainment of exposure (particularly missing data on radiological or standardized criteria for the assessment of OA; Supplementary Table 3). On the other, only one study has not considered pertinent linkage to high-quality records [42].

\section{Hazard ratios for overall mortality}

For the calculation of pooled overall mortality estimate we used joint-specific HRs for three studies [40-42]. Compared to those without OA, participants with OA had no significantly different risk for overall mortality (HR 1/4 1.10; 95\% CI: 0.97-1.25; p 1/4 0.12; I² 1/4 67\%; Fig.), also after adjusting for a median of 13 (IQR: 9-14) confounders (Supplementary Table 4). After excluding studies providing risks for site specific OA, the pooled risk of death from all causes was found to be significant with low heterogeneity (HR 1/4 1.18; 95\% CI: 1.08-1.28; p o $\left.0.001 ; \mathrm{I}^{2} 1 / 447 \%\right)$.

Subgroup analyses demonstrated that the presence of OA in hand, hip, and knee was not associated with an increased risk of mortality (Fig.). Funnel plot inspection indicated that publication bias was unlikely, as confirmed by Begg's (p 1/4 0.90) and Egger's tests (p 1/4 0.89).

Hazard ratios for cause-specific (CVD) mortality In four studies (PRO.V.A and [37,38,41]), OA was significantly associated with CVD death without heterogeneity or publication bias (HR 1/4 1.21; 95\% CI: 1.10-1.34; p o 0.001; $\mathrm{I}^{2} 1 / 40 \%$ ). Cause- specific mortality for single joints could not be computed due to the limited number of studies.

\section{Meta-regression analysis}

As the overall mortality analyses showed evidence of hetero- geneity ( $\left.\mathrm{I}^{2} 1 / 467 \%\right)$, a meta-regression analysis was undertaken (Table 4). In a great part of the strata heterogeneity remained high. However, in some studies there was a significantly higher risk of overall mortality and a moderate to substantial reduction of between-study heterogeneity—European studies; death ascertain- ment using death certificates; multiple joints affected; and radio- logical diagnosis of OA.

As the pooled HR for hand OA on overall mortality appeared to be marginally protective (p $1 / 40.07$ ), a sensitivity analysis was conducted to remove the effect of three datasets (PRO.V.A and [40,41]). This analysis demonstrated that for hand OA, pooled HR for mortality was 1.18 (95\% CI: 1.07-1.30; p 1/4 0.001; I I/4 48\%) (PRO.V.A and $[33-35,37,38])$. 


\section{Discussion}

To the best of our knowledge, this is the first meta-analysis investigating the association between OA and mortality. The seven meta-analyzed studies (including 10,018 participants with and 18,541 people without OA) demonstrated that the presence of OA was not associated with mortality, although this appeared to substantially depend on between-study heterogeneity. When analyzing studies conducted in Europe, we observed a significantly higher risk of mortality and lower heterogeneity. A significant

confounding factor to mortality seems to be the inclusion of the studies reporting data on hand OA. Finally, when considering cause-specific mortality, it appears that people with OA are at increased risk of CVD mortality.

It is known that participants with OA frequently exhibit a number of medical morbidities which increase their risk for death $[8,39,43]$. In the PRO.V.A. study, people with OA reported a higher presence of frailty, cardiovascular and metabolic diseases than those without. The role of these potential confounders in explain- ing the relationship between OA and mortality seems to be relevant [44], consistent with the findings of a recent large scale prospective study [37] reinforcing the importance of CVD risk in influencing mortality of people with OA. In the PRO.V.A. study we have tried to better identify the specific risk factors for mortality in participants with OA, in order to propose appropriate and specific interventions. Independent predictors of early death significantly different between those with OA and those without were diabetes, CVD, frailty, and poorer nutrition index. Hierarchi- cally, frailty seems to be the most important and, since frailty is reversible if appropriately treated [45], our findings suggest that people with OA should be more active to reduce the risk of premature death. Thus, the association between OA and overall mortality appears to be more related to confounders than for OA itself. This is likely supported in our meta-analysis by strata analysis as the number of adjustments appeared to partially explain between-study heterogeneity. Strata analyses suggested not only that ethnicity could be a potential risk modifier but also that evidence of an association may depend on study method- ology. Particularly, our study highlights the need of providing evidence based or at least consensus-based criteria for homoge- nous case ascertainment.

The secondary analyses explored whether the anatomical site of OA was associated with earlier mortality. Hip or knee OA did not predict early death, while for hand OA there was a trend towards a significant reduction in mortality. Since lower limbs OA are associated with high rate of disability and other risk factors for mortality [46], more research is needed to better understand the role of lower limbs OA in predicting mortality. Regarding hand OA, one study [40] suggests that not only radiographic but also symptomatic hand OA is protective for mortality, although both these conditions are associated with a higher incidence of CVD [40]. A possible reason is that hand OA was associated with a reduced cancer-related mortality [40]. The reasons of this associ- ation are not known and further research is obviously needed.

Our data from the meta-analysis suggests that people with OA are at increased risk of premature mortality due to CVD also after accounting for potential confounders. People with OA are known to have high levels of CVD [8,47], an increased inflammatory profile [9] and low levels of physical activity [48], all of which may predispose 
people with OA to premature mortality due to CVD. Moreover, they use a higher proportion of analgesic medications with an unfavorable CVD profile [49].Given that exercise has been reported as being equally effective in managing some types of CVD as pharmacological interventions [50], interventions targeting physical activity, frailty, and inappropriate medication should be a priority among people with OA at higher risk of mortality. An indirect confirmation of this hypothesis was given by a recent study showing that patients with knee OA who under- went joint replacement had a lower risk of future CVD events, potentially due to an increased postoperative physical activity levels and decreased use of analgesics when compared pre- operatively [51].

While our primary data and meta-analyses are novel, the findings of our work should be interpreted within its limitations. First, there was some evidence of statistical heterogeneity. How- ever, we attempted to address the issue of between study hetero- geneity, as advised by the MOOSE guidelines [24], suggesting some factors could moderate the association between OA and mortality. Second, it was not possible to stratify our meta-analysis results according to gender, although it is known that women are at higher risk of OA and its complications [52]. Third, no study included considered nor the duration of OA at inclusion, nor its progression (clinically or radiologically) neither the incidence of new cases within the follow-up period. It is therefore unclear whether OA disease progression influenced the outcomes. Fur- thermore, there was no record as what treatments were prescribed and adhered to in the OA cohort, which clearly might influence mortality. Therefore it is unclear whether disease medication (or symptom modification) impacted on mortality. Fourth, there was some discrepancy in the prevalence of OA across the PRO.V.A. study and the meta-analysis. Reasons for this difference may include (i) the higher mean age of the PRO.V.A. cohort and (ii) the potential higher prevalence of OA in Italy than in other countries [6]. Fifth, we did not assess the association of OA with specific cause mortality other than CVD mortality. This was because there remains limited evidence on other cause mortality for people with OA. Consequently such analyses would have been underpowered and potentially meaningless. However, this should be considered in the future once more studies are published in this area. Finally, the analyses pertaining to sitespecific OA are preliminary and should be interpreted with cautious. These are based on a limited number of studies for each outcome, and appeared to be contrasting (lower limbs OA seems to increase and hand OA seems to decrease the risk of death). Further analyses should be undertaken to re-explore the potential importance of joint location with mortality as more studies are published in this area

The strengths of this article are that it is the first meta-analysis to (i) assess for the association between OA and mortality and (ii) has specifically explored for factors to explain for the

heterogeneity in individual study results. This therefore provides important knowledge to increase the awareness of CVD in this population. This is important since CVD is potentially preventable through appropriate timely interventions [10] to impact on the health of people with osteoarthritis. Secondly, since the cohorts included in these analyses were large, the collective pooled analyses provided lower risk of committing a type two statistical error which would have occurred if these studies were interpreted individually. Finally, in the adjusted analyses, a number and wide variety of different confounders were included in the analysis to be able to answer our research question with these potential factors accounted for. 
In conclusion, it appears that people with OA are at increased risk of CVD-specific mortality while the association with overall mortality is less clear. Additional prospective research is required to further explore the relationship between OA and mortality.

\section{Funding sources}

The data collection phase of the PRO.V.A. study was supported by the Fondazione Cassa di Risparmio di Padova e Rovigo; the University of Padova (01/2014); the Azienda Unità Locale Socio Sanitaria 15 and 18 of the Veneto Region; and a grant from the Veneto Regional Authority (Ricerca Sanitaria Finalizzata no. 156/ 03). The data analysis phase was also financed by a grant from the University of Padova (Population aging — economics, health, retire- ment, and the welfare state_-POPA_EHR). The funding organiza- tions had no role in the design and conduction of the study; the collection, analysis, and interpretation of the data; or the prepa- ration, review, or approval of the article.

\section{Acknowledgments}

We would like to thank Dr. Marta Cecilia Castano Betancourt who gave some additional data about her article. 


\section{Appendix A. Supplementary material}

Supplementary data are available in the online version of this article at http://dx.doi.org/10.1016/j.semarthrit.2016.04.002

\section{References}

[1] Global Burden of Disease Study 2013 Collaborators. Global, regional, and national incidence, prevalence, and years lived with disability for 301 acute and chronic diseases and injuries in 188 countries, 1990-2013: a systematic analysis for the Global Burden of Disease Study 2013. Lancet 2015;386:743-800, http://dx.doi.org/10.1016/S0140-6736(15)60692-4.

[2] Cross M, Smith E, Hoy D, et al. The global burden of hip and knee osteo- arthritis: estimates from the Global Burden of Disease 2010 study. Ann Rheum Dis 2014;73:1323-30, http://dx.doi.org/10.1136/annrheumdis-2013-204763.

[3] Leveille SG, Bean J, Ngo L, McMullen W, Guralnik JM. The pathway from musculoskeletal pain to mobility difficulty in older disabled women. Pain 2007;128:69-77, http://dx.doi.org/10.1016/j.pain.2006.08.031.

[4] Wallis JA, Webster KE, Levinger P, Taylor NF. What proportion of people with hip and knee osteoarthritis meet physical activity guidelines? A systematic review and meta-analysis. Osteoarthritis Cartilage 2013;21:1648-59, http:

//dx.doi.org/10.1016/j.joca.2013.08.003.

[5] Biswas A, Oh PI, Faulkner GE, et al. Sedentary time and its association with risk for disease incidence, mortality, and hospitalization in adults. Ann Intern Med 2015;162:123, http://dx.doi.org/10.7326/M14-1651.

[6] van der Pas S, Castell MV, Cooper C, et al. European project on osteoarthritis: design of a six-cohort study on the personal and societal burden of osteo- arthritis in an older European population. BMC Musculoskelet Disord 2013;14:138, http://dx.doi.org/10.1186/1471-2474-14-138.

[7] Obesity, http://www.euro.who.int/en/health-topics/noncommunicable-dis- eases/obesity [accessed 20.11.15].

[8] Hall AJ, Stubbs B, Mamas MA, Myint PK, Smith TO. Association between osteoarthritis and cardiovascular disease: systematic review and meta- analysis. Eur J Prev Cardiol 2015. http://dx.doi.org/10.1177/2047487315610663.

[9] Greene MA, Loeser RF. Aging-related inflammation in osteoarthritis. Osteo- arthritis Cartilage 2015;23:1966-71, http://dx.doi.org/10.1016/j.joca.2015 .01.008.

[10] Mills EJ, Rachlis B, Wu P, Devereaux PJ, Arora P, Perri D. Primary prevention of cardiovascular mortality and events with statin treatments: a network meta- analysis involving more than 65,000 patients. J Am Coll Cardiol 2008;52: 1769-81, http://dx.doi.org/10.1016/j.jacc.2008.08.039.

[11] Hochberg MC. Mortality in osteoarthritis. [accessed 20.11.15]. Clin Exp Rheu- matol 2008;26(5 Suppl. 51):S120-4.

$\langle$ http://www.ncbi.nlm.nih.gov/pubmed/ 19026154〉 [accessed 20.11.15]. 
[12] Nüesch E, Dieppe P, Reichenbach S, Williams S, Iff S, Jüni P. All cause and disease specific mortality in patients with knee or hip osteoarthritis: pop- ulation based cohort study. Br Med J 2011;342:d1165. 〈http://www.pubmed central.nih.gov/articlerender.fcgi?artid=3050438\&tool=pmcentrez\&rendertype= abstract $\rangle$ [accessed 03.11.15].

[13] Liu R, Kwok WY, Vliet Vlieland TP, et al. Mortality in osteoarthritis patients consulting health care. Scand J Rheumatol 2015;44:70-3, http://dx.doi.org/ 10.1016/j.joca.2012.02.226.

[14] Corti M-C, Guralnik JM, Sartori L, et al. The effect of cardiovascular and osteoarticular diseases on disability in older Italian men and women: ration- ale, design, and sample characteristics of the Progetto Veneto Anziani (PRO.V. A.) study. J Am Geriatr Soc 2002;50:1535-40. 〈http://www.ncbi.nlm.nih.gov/ pubmed/12383151〉 [accessed 03.11.15].

[15] Veronese N, Maggi S, Noale M, et al. Serum 25-hydroxyvitamin D and osteoarthritis in older people: the progetto veneto anziani study. Rejuvenation Res 2015. http://dx.doi.org/10.1089/rej.2015.1671.

[16] American Autonomic Society and the American Academy of Neurology. Consensus statement on the definition of orthostatic hypotension, pure autonomic failure, and multiple system atrophy. The Consensus Committee of the American Autonomic Society and the American Academy of Neurology. Neurology 1996;46:1470. 〈http://www.ncbi.nlm.nih.gov/pubmed/8628505〉 [accessed 08.09.15].

[17] Pickering TG, Hall JE, Appel LJ, et al. Recommendations for blood pressure measurement in humans and experimental animals: Part 1: blood pressure measurement in humans: a statement for professionals from the Subcommit- tee of Professional and Public Education of the American Heart Association Council on high blood pressure research. Hypertension 2005;45:142-61, http: //dx.doi.org/10.1161/01.HYP.0000150859.47929.8e.

[18] American Diabetes Association. 2. Classification and diagnosis of diabetes. Diabetes Care 2014;38(Suppl. 1):S8-16, http://dx.doi.org/10.2337/dc15-S005.

[19] Sergi G, Veronese N, Fontana L, et al. Pre-frailty and risk of cardiovascular disease in elderly men and women: the Pro.V.A. study. J Am Coll Cardiol 2015;65:976-83, http://dx.doi.org/10.1016/j.jacc.2014.12.040.

[20] Katz S, Downs TD, Cash HR, Grotz RC. Progress in development of the index of ADL. Gerontologist 1970;10:20-30. $\langle$ http://www.ncbi.nlm.nih.gov/pubmed/ 5420677〉 [accessed 20.07.15].

[21] Folstein MF, Robins LN, Helzer JE. The mini-mental state examination. Arch Gen Psychiatry 1983;40:812. http://dx.doi.org/10.1001/archpsyc.1983. 01790060110016.

[22] Yesavage JA, Brink TL, Rose TL, et al. Development and validation of a geriatric depression screening scale: a preliminary report. [accessed 25.08.14]. J Psychiatr Res 1982-1983;17:37-49. 〈http://www.ncbi.nlm.nih.gov/pubmed/ 7183759.〉 [accessed 25.08.14].

[23] Cereda E, Pedrolli C. The geriatric nutritional risk index. Curr Opin Clin Nutr Metab Care 2009;12:1-7, http://dx.doi.org/10.1097/MCO.0b013e3283186f59. 
[24] Stroup DF, Berlin J a, Morton SC, et al. Meta-analysis of observational studies in epidemiology: a proposal for reporting. Metaanalysis Of Observational Studies in Epidemiology (MOOSE) group. J Am Med Assoc 2000;283:2008-12, http://dx.doi.org/10.1001/jama.283.15.2008.

[25] Liberati A, Altman DG, Tetzlaff J, et al. The PRISMA statement for reporting systematic reviews and meta-analyses of studies that evaluate health care interventions: explanation and elaboration. PLoS Med 2009;6:e1000100, http:

//dx.doi.org/10.1371/journal.pmed.1000100.

[26] Wells G, Shea B, O'Connell D, et al. The Newcastle-Ottawa Scale (NOS) for assessing the quality if nonrandomized studies in meta-analyses, Available from 〈http//www.ohri.ca/programs/clinical_epidemiology/oxford.asp〉; 2012:2012. doi:10.2307/632432.

[27] DerSimonian R, Laird N. Meta-analysis in clinical trials. Control Clin Trials 1986;7:177-88, http://dx.doi.org/10.1016/01972456(86)90046-2.

[28] Higgins JPT, Thompson SG, Deeks JJ, Altman DG. Measuring inconsistency in meta-analyses. Br Med J. 2003;327:557-60, http://dx.doi.org/10.1136/bmj. 327.7414.557.

[29] Altman R, Alarcón G, Appelrouth D, et al. The American College of Rheuma- tology criteria for the classification and reporting of osteoarthritis of the hand. Arthritis Rheum 1990;33:1601-10. 〈http://www.ncbi.nlm.nih.gov/pubmed/ 2242058〉 [accessed 02.02.16].

[30] Altman R, Alarcón G, Appelrouth D, et al. The American College of Rheuma- tology criteria for the classification and reporting of osteoarthritis of the hip. Arthritis Rheum 1991;34:505-14. 〈http://www.ncbi.nlm.nih.gov/pubmed/ 2025304〉 [accessed 05.01.16].

[31] Wu CW, Morrell MR, Heinze E, et al. Validation of American College of Rheumatology classification criteria for knee osteoarthritis using arthroscopi- cally defined cartilage damage scores. Semin Arthritis Rheum 2005;35: 197-201, http://dx.doi.org/10.1016/j.semarthrit.2005.06.002.

[32] Kinds MB, Welsing PMJ, Vignon EP, et al. A systematic review of the association between radiographic and clinical osteoarthritis of hip and knee. Osteoarthritis Cartilage 2011;19:768-78, http://dx.doi.org/10.1016/j.joca. 2011.01.015.

[33] Higgins JPT, Thompson SG. Quantifying heterogeneity in a meta-analysis. Stat Med 2002;21:1539-58, http://dx.doi.org/10.1002/sim.1186.

[34] Begg CB, Mazumdar M. Operating characteristics of a rank correlation test for publication bias. Biometrics 1994;50:1088-101, http://dx.doi.org/10.2307/ 2533446.

[35] Egger M, Davey Smith G, Schneider M, Minder C. Bias in meta-analysis detected by a simple, graphical test. Br Med J 1997;315:629-34, http://dx. doi.org/10.1136/bmj.316.7129.469.

[36] Duval S, Tweedie R. Trim and fill: a simple funnel-plot-based method of testing and adjusting for publication bias in metaanalysis. Biometrics 2000;56:455-63, http://dx.doi.org/10.1111/j.0006-341x.2000.00455.x. 
[37] Barbour KE, Lui L-Y, Nevitt MC, et al. PROOF VERSION—hip osteoarthritis and the risk of all-cause and disease-specific mortality in older women: population-based cohort study. Arthritis Rheumatol 2015. http://dx.doi.org/ 10.1002/art.39113.

[38] Castano Betancourt MC, Dehghan A, Campos N, et al. Osteoarthritis and mortality: meta-analysis of two prospective cohorts. Osteoarthr Cartil 2013;21:S151, http://dx.doi.org/10.1016/j.joca.2013.02.324.

[39] Cacciatore F, Della-Morte D, Basile C, et al. Long-term mortality in frail elderly subjects with osteoarthritis. Rheumatology (Oxford) 2014;53:293-9, http: //dx.doi.org/10.1093/rheumatology/ket348.

[40] Haugen IK, Ramachandran VS, Misra D, et al. Hand osteoarthritis in relation to mortality and incidence of cardiovascular disease: data from the Framingham Heart Study. Ann Rheum Dis 2015;74:74-81, http://dx.doi.org/10.1136/annr- heumdis-2013203789.

[41] Kluzek S, Sanchez-Santos MT, Leyland KM, et al. Painful knee but not hand osteoarthritis is an independent predictor of mortality over 23 years follow-up of a population-based cohort of middle-aged women. Ann Rheum Dis 2015. http://dx.doi.org/10.1136/annrheumdis-2015-208056.

[42] Liu Q, Niu J, Huang J, et al. Knee osteoarthritis and all-cause mortality: the Wuchuan Osteoarthritis Study. Osteoarthritis Cartilage 2015;23:1154-7, http: //dx.doi.org/10.1016/j.joca.2015.03.021.

[43] Johnson VL, Hunter DJ. The epidemiology of osteoarthritis. Best Pract Res Clin Rheumatol 2014;28:5-15, http://dx.doi.org/10.1016/j.berh.2014.01.004.

[44] Hoeven TA, Leening MJG, Bindels PJ, et al. Disability and not osteoarthritis predicts cardiovascular disease: a prospective population-based cohort study. Ann Rheum Dis 2015;74:752-6, http://dx.doi.org/10.1136/annrheumdis-2013- 204388.

[45] Villareal DT, Banks M, Sinacore DR, Siener C, Klein S. Effect of weight loss and exercise on frailty in obese older adults. Arch Intern Med 2006;166:860-6, http://dx.doi.org/10.1001/archinte.166.8.860.

[46] van Dijk GM, Veenhof C, Lankhorst GJ, Dekker J. Limitations in activities in patients with osteoarthritis of the hip or knee: the relationship with body functions, comorbidity and cognitive functioning. Disabil Rehabil 2009;31: 1685-91, http://dx.doi.org/10.1080/09638280902736809.

[47] Veronese N, Trevisan C, De Rui M, et al. Osteoarthritis increases the risk of cardiovascular diseases in the elderly: the progetto veneto anziano study. Arthritis Rheumatol (Hoboken, NJ) 2015. http://dx.doi.org/10.1002/art.39564.

[48] Stubbs B, Hurley M, Smith T. What are the factors that influence physical activity participation in adults with knee and hip osteoarthritis? A systematic review of physical activity correlates. Clin Rehabil 2015;29:80-94, http://dx. doi.org/10.1177/0269215514538069.

[49] Capone ML, Tacconelli S, Rodriguez LG, Patrignani P. NSAIDs and cardiovas- cular disease: transducing human pharmacology results into clinical read-outs in the general population. [accessed 12.12.15]. Pharmacol Rep 2010;62:530-5.

〈http://www.ncbi.nlm.nih.gov/pubmed/20631418.〉 [accessed 12.12.15].

[50] Naci H, Ioannidis JPA. Comparative effectiveness of exercise and drug inter- ventions on mortality outcomes: metaepidemiological study. Br Med J 2013;347:f5577. 〈http://www.pubmedcentral.nih.gov/articlerender.fcgi?artid= 3788175\&tool=pmcentrez\&rendertype=abstract $\rangle \quad$ [accessed 12.12.15]. 
[51] Lin W-Y, Lee C-C, Hsu C-W, Huang K-Y, Lyu S-R. Patients with knee osteoarthritis undergoing total knee arthroplasty have a lower risk of subsequent severe cardiovascular events: propensity score and instrumental variable analysis. PLoS One 2015;10:e0127454, http://dx.doi.org/10.1371/journal.pone.0127454.

[52] O’Connor MI. Sex differences in osteoarthritis of the hip and knee. J Am Acad Orthop Surg 2007;15(Suppl. 1):S22-5. $\langle$ http://www.ncbi.nlm.nih.gov/ pubmed/17766785〉 [accessed 20.11.15].

\section{Legend to Figures}

Figure 1. Meta-analysis and pooled hazard ratios of mortality in participants with osteoarthritis from prospective cohort studies (*, for this study the estimate was obtained by pooling within-study risks for symptomatic and radiographic osteoarthritis; **, for this study the estimate was obtained by meta-analysing within-study risks for different joints after pooling hazard ratios for only symptomatic, only radiographic and painful radiographic osteoarthritis). 
Table 1. Baseline characteristics by diagnosis of osteoarthritis at baseline: the PRO.V.A. study.

\begin{tabular}{|c|c|c|c|}
\hline Patients' characteristics & $\begin{array}{c}\text { OA } \\
(n=1,858)\end{array}$ & $\begin{array}{c}\text { No OA } \\
(n=1,069)\end{array}$ & p value* \\
\hline Age (years), Mean \pm SD & $77.5 \pm 7.9$ & $74.6 \pm 7.6$ & $<0.001^{\dagger}$ \\
\hline Female gender, \% & 66.4 & 48.2 & $<0.001^{\ddagger}$ \\
\hline \multicolumn{4}{|l|}{ General and anthropometric characteristics } \\
\hline Alcohol drinking, \% & 65.1 & 72.8 & $<0.001$ \\
\hline Current smokers, \% & 6.3 & 13.0 & $<0.001$ \\
\hline Educational level $>5$ years, $\%$ & 13.0 & 17.4 & 0.002 \\
\hline Physical activity $\geq 4 \mathrm{~h} /$ week, $\%$ & 19.0 & 22.8 & $<0.001$ \\
\hline Monthly income ( $\geq 500 €), \%$ & 36.1 & 44.7 & $<0.001$ \\
\hline GNRI (score), Mean \pm SD & $105.6 \pm 5.7$ & $106.5 \pm 5.6$ & 0.048 \\
\hline ADL (score), Mean \pm SD & $4.6 \pm 1.8$ & $5.4 \pm 1.4$ & $<0.001$ \\
\hline BMI $\left(\mathbf{k g} / \mathbf{m}^{2}\right)$, Mean \pm SD & $28.0 \pm 4.8$ & $26.8 \pm 4.2$ & $<0.001$ \\
\hline GDS (score), Mean \pm SD & $9.5 \pm 6.0$ & $8.1 \pm 5.0$ & $<0.001$ \\
\hline MMSE (score), Mean \pm SD & $22.3 \pm 7.0$ & $23.8 \pm 6.2$ & 0.51 \\
\hline \multicolumn{4}{|l|}{ Medical conditions } \\
\hline Frailty, \% & 12.6 & 4.9 & $<0.001$ \\
\hline Fractures, \% & 11.6 & 5.9 & $<0.001$ \\
\hline Diabetes, \% & 17.7 & 14.7 & 0.03 \\
\hline Hypertension, \% & 76.3 & 70.8 & 0.001 \\
\hline Orthostatic hypotension, \% & 34.1 & 28.8 & 0.004 \\
\hline CVD, \% & 25.5 & 20.4 & 0.002 \\
\hline COPD, \% & 10.0 & 9.1 & 0.44 \\
\hline Cancer, \% & 7.9 & 7.4 & 0.67 \\
\hline Number of drugs, Mean \pm SD & $3.1 \pm 2.2$ & $2.4 \pm 2.1$ & $<0.001$ \\
\hline
\end{tabular}

*Unless otherwise specified, p values are adjusted for age and gender using a general linear model or logistic regression, as appropriate.

${ }^{\dagger}$ Not adjusted for age.

${ }^{\ddagger}$ Not adjusted for gender.

Abbreviations: ADL: activities of daily living; BMI: body mass index; COPD: chronic obstructive pulmonary disease; CVD: cardiovascular diseases; GDS: Geriatric Depression Scale; GNRI: Geriatric Nutrition Risk Index; MMSE: Mini Mental State Examination; OA: osteoarthritis; SD, standard deviation. 
Table 2: Association of osteoarthritis (OA) with the onset of all-cause mortality in the PRO.V.A. study cohort.

\begin{tabular}{|ccccccc|}
\hline & $\begin{array}{c}\text { Events } \\
(\mathrm{N})\end{array}$ & $\begin{array}{c}\text { Participants } \\
(\mathrm{N})\end{array}$ & $\begin{array}{c}\text { Unadjusted } \\
\text { HR (95\%CI) }\end{array}$ & $\begin{array}{c}\boldsymbol{p} \text { - } \\
\text { value }\end{array}$ & $\begin{array}{c}\text { Fully-adjusted } \\
\text { HR (95\%CI) }\end{array}$ & $\begin{array}{c}\boldsymbol{p} \text { - } \\
\text { value }\end{array}$ \\
\hline No OA & 241 & 1,068 & reference & reference & \\
Presence of OA & 504 & 1,857 & $1.16(0.96-1.40)$ & 0.12 & $0.95(0.78-1.16)$ & 0.59 \\
\hline Hand OA & 180 & 695 & $1.13(0.89-1.43)$ & 0.33 & $1.00(0.78-1.29)$ & 0.99 \\
Hip OA & 231 & 966 & $1.07(0.87-1.33)$ & 0.52 & $0.96(0.77-1.20)$ & 0.70 \\
Knee OA & 140 & 549 & $1.05(0.81-1.35)$ & 0.74 & $0.86(0.66-1.12)$ & 0.27 \\
\hline
\end{tabular}

Data are presented as hazard ratios and 95\% confidence intervals [HR (95\%CI)].

*The fully-adjusted model includes: age (continuous); gender; body mass index (continuous); educational level ( $\leq 5$ vs. $>5$ years); alcohol drinking (yes vs. no); monthly income ( $\geq 500$ vs. $<500$ $€$ ); physical activity level ( $\geq 4$ vs. $<4 \mathrm{~h} /$ week); presence at baseline of cardiovascular diseases, fractures, chronic obstructive pulmonary disease, orthostatic hypotension, hypertension, diabetes, frailty, cancer (all yes vs. no); number of medications (continuous); smoking status (current vs. no/former); Activities of Daily Living, Mini-Mental State, Geriatric Depression Scale, Geriatric Nutrition Risk Index scores (all as continuous). 
Table 3. Characteristics of the studies according to the presence of osteoarthritis or not.

\begin{tabular}{|c|c|c|c|c|c|c|c|c|c|c|c|c|c|}
\hline $\begin{array}{c}\text { First } \\
\text { author, } \\
\text { year }\end{array}$ & $\begin{array}{l}\text { Continent } \\
\text { (Country) }\end{array}$ & Setting & $\begin{array}{c}\text { Diagnosis } \\
\text { criteria for } \\
\text { OA }\end{array}$ & $\mathbf{O A}$ & $\mathbf{N}$ & $\begin{array}{l}\text { Mean age } \\
\text { (SD) }\end{array}$ & $\begin{array}{c}\text { Females } \\
\text { (N) }\end{array}$ & $\begin{array}{c}\text { CVD } \\
\text { (N) }\end{array}$ & $\begin{array}{c}\text { Mean BMI } \\
\text { (SD) }\end{array}$ & $\begin{array}{c}\text { Death } \\
\text { ascertainment }\end{array}$ & $\begin{array}{c}\text { Follow- } \\
\text { up } \\
\text { (years) }\end{array}$ & $\begin{array}{l}\text { Adjustments } \\
\text { (N) }\end{array}$ & $\begin{array}{l}\text { NOS } \\
\text { score }\end{array}$ \\
\hline \multirow{2}{*}{$\begin{array}{l}\text { Barbour, } \\
2015\end{array}$} & \multirow{2}{*}{$\begin{array}{l}\text { North America } \\
\text { (USA) }\end{array}$} & \multirow{2}{*}{ Community } & \multirow{2}{*}{ Radiological } & Yes & 635 & $72.7(5.3)$ & 635 & 53 & $26.7(4.6)$ & \multirow{2}{*}{$\begin{array}{c}\text { Phone calls + } \\
\text { death certificates }\end{array}$} & \multirow{2}{*}{16} & \multirow{2}{*}{7} & \multirow{2}{*}{8} \\
\hline & & & & No & 7254 & $71.2(5.0)$ & 7254 & 464 & $26.5(4.6)$ & & & & \\
\hline \multirow{2}{*}{$\begin{array}{c}\text { Castano } \\
\text { Betancourt, } \\
2013\end{array}$} & \multirow{2}{*}{$\begin{array}{l}\text { Europe (The } \\
\text { Netherlands) }\end{array}$} & \multirow[b]{2}{*}{ Community } & \multirow[b]{2}{*}{ Radiological } & Yes & 4733 & $\geq 55$ & 2721 & -- & -- & \multirow[b]{2}{*}{ GP records } & \multirow[b]{2}{*}{5} & \multirow[b]{2}{*}{11} & \multirow[b]{2}{*}{7} \\
\hline & & & & No & 6261 & $\geq 55$ & -- & -- & -- & & & & \\
\hline \multirow{2}{*}{$\begin{array}{l}\text { Cacciatore, } \\
2014\end{array}$} & \multirow{2}{*}{ Europe (Italy) } & \multirow{2}{*}{ Community } & \multirow{2}{*}{$\begin{array}{c}\text { Clinical + } \\
\text { Radiological }\end{array}$} & Yes & 698 & 74.8 (6.5) & 559 & -- & $27.0(5.1)$ & \multirow{2}{*}{ Death certificates } & \multirow{2}{*}{12} & \multirow{2}{*}{13} & \multirow{2}{*}{6} \\
\hline & & & & No & 590 & 72.7 (6.9) & 175 & -- & $25.8(4.5)$ & & & & \\
\hline \multirow{2}{*}{$\begin{array}{l}\text { Haugen, } \\
2015\end{array}$} & \multirow{2}{*}{$\begin{array}{l}\text { North America } \\
\text { (USA) }\end{array}$} & \multirow{2}{*}{ Community } & \multirow{2}{*}{$\begin{array}{c}\text { Clinical + } \\
\text { Radiological }\end{array}$} & Yes & 1162 & $66.3(7.6)$ & 422 & 55 & $27.9(4.6)$ & \multirow{2}{*}{$\begin{array}{c}\text { Linkage to } \\
\text { different } \\
\text { registries }\end{array}$} & \multirow{2}{*}{20} & \multirow{2}{*}{14} & \multirow{2}{*}{9} \\
\hline & & & & No & 622 & $57.6(6.4)$ & 303 & 37 & $27.4(4.5)$ & & & & \\
\hline \multirow{2}{*}{$\begin{array}{l}\text { Kluzek, } \\
2015\end{array}$} & \multirow{2}{*}{ Europe (UK) } & \multirow{2}{*}{ Community } & Clinical + & Yes & 689 & $57.5(6.0)$ & 709 & 31 & -- & Death certificates & 23 & 13 & 9 \\
\hline & & & Radiological & No & 940 & $55.0(5.7)$ & 940 & 35 & -- & & & & \\
\hline Liu, 2015 & Asia (China) & Community & $\begin{array}{l}\text { Clinical + } \\
\text { Radiolơical }\end{array}$ & Yes & 244 & $\begin{array}{c}62.0 \\
(10.2)\end{array}$ & 163 & -- & $23.7(3.7)$ & Interview with & 8 & 7 & 8 \\
\hline & & & & No & 1806 & $56.0(7.7)$ & 877 & -- & -- & & & & \\
\hline PRO.V.A. & Europe (Italv) & Community & Clinical + & Yes & 1857 & 77.5 (7.9) & 1233 & 473 & $28.0(4.8)$ & Death certificates & 4 & 21 & 7 \\
\hline study & & & Radiological & No & 1068 & $74.6(7.6)$ & 515 & 218 & $26.8(4.2)$ & & & & \\
\hline
\end{tabular}

Abbreviations: BMI: body mass index; CVD: cardiovascular disease; GP: general practitioner; NOS score: Newcastle Ottawa scale score; OA: osteoarthritis; SD: standard deviation. 
Table 4. Adjusted all-cause mortality risk for strata of different moderators

\begin{tabular}{|c|c|c|c|}
\hline Moderator & Strata & Analysis details & Adjusted HRs \\
\hline Continent & 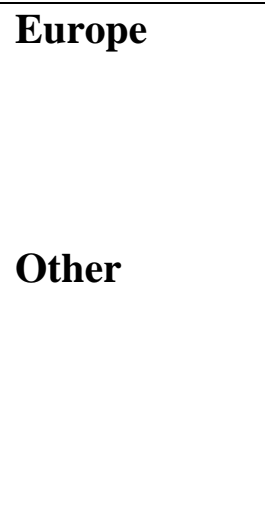 & $\begin{array}{l}\text { Pooled estimate, HR (95\%CI) } \\
\text { P-value for HR } \\
\text { Heterogeneity, } I^{2} \text { (P-value) } \\
\text { Number of studies } \\
\text { Pooled estimate, HR (95\%CI) } \\
\text { P-value for HR } \\
\text { Heterogeneity, } I^{2} \text { (P-value) } \\
\text { Number of studies } \\
\text { P-value }\end{array}$ & $\begin{array}{l}\mathbf{1 . 1 8}(\mathbf{1 . 0 8 - 1 . 2 8 )} \\
<0.001 \\
47 \%(0.13) \\
4 \\
1.06(0.80-1.25) \\
0.68 \\
82 \%(0.004) \\
3 \\
0.82\end{array}$ \\
\hline Study quality $^{\dagger}$ & $\begin{array}{l}\text { NOS score } \leq 7 \\
\text { NOS score }>7\end{array}$ & $\begin{array}{l}\text { Pooled estimate, HR (95\%CI) } \\
\text { P-value for HR } \\
\text { Heterogeneity, } I^{2} \text { (P-value) } \\
\text { Number of studies } \\
\text { Pooled estimate, HR (95\%CI) } \\
\text { P-value for HR } \\
\text { Heterogeneity, } I^{2} \text { (P-value) } \\
\text { Number of studies } \\
\text { P-value* }\end{array}$ & $\begin{array}{l}1.14(0.96-1.36) \\
0.13 \\
64 \%(0.06) \\
3 \\
1.09(0.84-1.39) \\
0.53 \\
74 \%(0.01) \\
4 \\
0.74\end{array}$ \\
\hline$\underset{\dagger}{\text { Number of adjustments }}$ & $\geq 13$ & $\begin{array}{l}\text { Pooled estimate, HR (95\%CI) } \\
\text { P-value for HR } \\
\text { Heterogeneity, } I^{2} \text { (P-value) } \\
\text { Number of studies } \\
\text { Pooled estimate, HR (95\%CI) } \\
\text { P-value for HR } \\
\text { Heterogeneity, } I^{2} \text { (P-value) } \\
\text { Number of studies } \\
\text { P-value * }\end{array}$ & $\begin{array}{l}\mathbf{1 . 1 8}(\mathbf{1 . 1 0 - 1 . 2 7 )} \\
<0.0001 \\
8 \%(0.34) \\
3 \\
1.00(0.81-1.26) \\
0.95 \\
63 \%(0.05) \\
4 \\
0.18\end{array}$ \\
\hline Follow-up duration ${ }^{\dagger}$ & $<15$ & $\begin{array}{l}\text { Pooled estimate, HR (95\%CI) } \\
\text { P-value for HR } \\
\text { Heterogeneity, } I^{2} \text { (P-value) } \\
\text { Number of studies } \\
\text { Pooled estimate, HR (95\%CI) } \\
\text { P-value for HR } \\
\text { Heterogeneity, } I^{2} \text { (P-value) } \\
\text { Number of studies } \\
\text { P-value* }\end{array}$ & $\begin{array}{l}\mathbf{1 . 1 7}(\mathbf{1 . 0 0 - 1 . 3 8 )} \\
0.05 \\
53 \%(0.09) \\
4 \\
1.02(0.76-1.36) \\
0.91 \\
79 \%(0.008) \\
3 \\
0.39\end{array}$ \\
\hline
\end{tabular}




\begin{tabular}{|c|c|c|c|}
\hline Diagnosis of death & $\begin{array}{l}\text { Death } \\
\text { certificates }\end{array}$ & $\begin{array}{l}\text { Pooled estimate, HR (95\%CI) } \\
\text { P-value for HR } \\
\text { Heterogeneity, } I^{2} \text { (P-value) } \\
\text { Number of studies } \\
\text { Pooled estimate, HR (95\%CI) } \\
\text { P-value for HR } \\
\text { Heterogeneity, } I^{2} \text { (P-value) } \\
\text { Number of studies } \\
\text { P-value* }\end{array}$ & $\begin{array}{l}\mathbf{1 . 1 8}(\mathbf{1 . 0 8 - 1 . 2 8 )} \\
<0.001 \\
47 \%(0.13) \\
4 \\
1.06(0.80-1.25) \\
0.68 \\
82 \%(0.004) \\
3 \\
0.82\end{array}$ \\
\hline $\begin{array}{l}\text { Diagnosis of } \\
\text { osteoarthritis }\end{array}$ & $\begin{array}{l}\text { Radiological + } \\
\text { clinical }\end{array}$ & $\begin{array}{l}\text { Pooled estimate, HR (95\%CI) } \\
\text { P-value for HR } \\
\text { Heterogeneity, } I^{2} \text { (P-value) } \\
\text { Number of studies } \\
\text { Pooled estimate, HR (95\%CI) } \\
\text { P-value for HR } \\
\text { Heterogeneity, } I^{2} \text { (P-value) } \\
\text { Number of studies } \\
\text { P-value* }\end{array}$ & $\begin{array}{l}1.07(0.85-1.34) \\
0.57 \\
65 \%(0.02) \\
5 \\
\mathbf{1 . 1 8 ( 1 . 0 9 - 1 . 2 7 )} \\
<0.001 \\
19 \%(0.27) \\
2 \\
0.42\end{array}$ \\
\hline Sites investigated & $\begin{array}{l}\text { Only one joint } \\
\text { More joints }\end{array}$ & $\begin{array}{l}\text { Pooled estimate, HR (95\%CI) } \\
\text { P-value for HR } \\
\text { Heterogeneity, } I^{2} \text { (P-value) } \\
\text { Number of studies } \\
\text { Pooled estimate, HR (95\%CI) } \\
\text { P-value for HR } \\
\text { Heterogeneity, } I^{2} \text { (P-value) } \\
\text { Number of studies } \\
\text { P-value* }\end{array}$ & $\begin{array}{l}1.06(0.80-1.41) \\
0.68 \\
82 \%(0.004) \\
3 \\
\mathbf{1 . 1 8 ( 1 . 0 8 - 1 . 2 8 )} \\
<0.001 \\
47 \%(0.13) \\
4 \\
0.61\end{array}$ \\
\hline
\end{tabular}

Bolded HR values: $\mathrm{p}<0.05$

Abbreviations: HR: hazard ratio; NOS: Newcastle-Ottawa Scale

* The P-value for the t-test between the two statistical analysis strata according to meta-regression procedure.

+ Stratification was performed by median NOS score, median follow-up time and median number of adjustments as appropriate. 
Supplementary Table 1: Search terms adopted for the search strategy

1. Osteoarthritis

2. Arthritis

3. Osteo\$

4. AND

5. Mortality

6. Death

7. premature mortality

8. $1+5$

9. $1+6$

10. $1+7$

11. $2+5$

12. $2+6$

13. $2+7$

14. $3+5$

15. $3+6$

16. $3+7$ 
Supplementary Table 2. Newcastle-Ottawa Scale (NOS) table: methodological quality of cohort studies included in the meta-analysis*

\begin{tabular}{|c|c|c|c|c|c|c|c|c|c|}
\hline $\begin{array}{c}\text { First author, } \\
\text { publication year }\end{array}$ & $\begin{array}{c}\text { Representativene } \\
\text { ss } \\
\text { of the exposed } \\
\text { cohort }\end{array}$ & $\begin{array}{c}\text { Selection of } \\
\text { the } \\
\text { unexposed } \\
\text { cohort }\end{array}$ & $\begin{array}{c}\text { Ascertainmen } \\
\mathbf{t} \\
\text { of exposure }^{\dagger}\end{array}$ & $\begin{array}{c}\text { Outcome of } \\
\text { interest not } \\
\text { present at } \\
\text { start of } \\
\text { study }^{\ddagger}\end{array}$ & $\begin{array}{c}\text { Control for } \\
\text { important } \\
\text { factor or } \\
\text { additional } \\
\text { factor }^{\S}\end{array}$ & $\begin{array}{l}\text { Assessment } \\
\text { of outcome }\end{array}$ & $\begin{array}{c}\text { Follow-up } \\
\text { long } \\
\text { enough for } \\
\text { outcome } \\
\text { to occur }\end{array}$ & $\begin{array}{l}\text { Follow-up } \\
\text { of cohort } \\
\text { adequate }\end{array}$ & $\begin{array}{l}\text { Total } \\
\text { quality } \\
\text { score }\end{array}$ \\
\hline Barbour, 2015 & $*$ & $*$ & $*$ & $*$ & $*$ & $*$ & $*$ & $*$ & 8 \\
\hline Castano Betancourt, 2013 & $*$ & - & $*$ & * & * & $*$ & $*$ & $*$ & 7 \\
\hline Cacciatore, 2014 & $*$ & $*$ & - & - & $*$ & $*$ & $*$ & $*$ & 6 \\
\hline Haugen, 2015 & $*$ & $*$ & $*$ & $*$ & $* *$ & $*$ & $*$ & $*$ & 9 \\
\hline Kluzek, 2015 & $*$ & $*$ & $*$ & $*$ & $* *$ & $*$ & $*$ & $*$ & 9 \\
\hline Liu, 2015 & $*$ & $*$ & $*$ & - & $* *$ & $*$ & $*$ & $*$ & 8 \\
\hline PRO.V.A. study & $*$ & $*$ & - & $*$ & $* *$ & * & - & $*$ & 7 \\
\hline
\end{tabular}

* A study could be awarded a maximum of one star for each item except for the item Control for important factor or additional factor. The definition/explanation of each column of the Newcastle-Ottawa Scale is available at

http://www.ohri.ca/programs/clinical_epidemiology/oxford.htm.

${ }^{\dagger}$ For this index, one star was given if in Method section OA was defined according with standard criteria or radiological exams for all participants were reported. 
‡ Being outcome of interest mortality, we took as outcome of interest for assessment of quality if specific-cause mortality was reported or autopsy was used for the ascertainment of the death.

$\S$ A maximum of 2 stars could be awarded for this item. Studies that controlled their survival analyses for at least five confounders received one star, whereas studies presenting data according to site of OA (hand, hip and/or knee) received an additional star.

" A cohort study with a mean/median follow-up time $\geq 5 \mathrm{y}$ (60 months) takes one star; if the mean follow-up is not clearly indicated: no star. 
Supplementary Table 3. Type and number of adjustments (in addiction of osteoarthritis) for each study.

\begin{tabular}{|c|c|c|}
\hline $\begin{array}{c}\text { First author, } \\
\text { publication year }\end{array}$ & Adjustments & $\begin{array}{l}\text { Number of } \\
\text { adjustments }\end{array}$ \\
\hline Barbour, 2015 & Age, body mass index, education, smoking, health status, diabetes, stroke & 7 \\
\hline Castano Betancourt, 2013 & $\begin{array}{l}\text { Age, gender, cohort study, smoking, diabetes, cardiovascular diseases, dementia, body } \\
\text { mass index, walking disability, analgesic-use, functional limitations }\end{array}$ & 11 \\
\hline Cacciatore, 2014 & $\begin{array}{l}\text { Age, gender, body mass index, waist circumference, heart rate, pulse blood pressure, } \\
\text { Charlson co-morbidity index, number of drugs, use of not steroidal anti-inflammatory } \\
\text { drugs, corticosteroids, disability, geriatric depression scale, frailty }\end{array}$ & 13 \\
\hline Haugen, 2015 & $\begin{array}{l}\text { Age, sex, cohort, body mass index, total cholesterol:HDL ratio, current lipid lowering } \\
\text { treatment, hypertension, current antihypertensive treatment, elevated fasting or non- } \\
\text { fasting blood glucose, current anti-diabetic treatment (oral or insulin), current use of not } \\
\text { steroidal anti-inflammatory drugs, daily use of aspirin, current/previous smoking, } \\
\text { alcohol use }\end{array}$ & 14 \\
\hline Kluzek, 2015 & $\begin{array}{c}\text { Age, smoking, total cholesterol, HDL-cholesterol, systolic blood pressure, use of anti- } \\
\text { hypertensive drugs, occupation, body mass index, hormonal replacement therapy use, } \\
\text { past physical activity, current/previous cardiovascular disease, not steroidal anti- } \\
\text { inflammatory drugs, plasma glucose levels }\end{array}$ & 13 \\
\hline Liu, 2015 & $\begin{array}{c}\text { Age, sex, body mass index, income level, education, levels of occupational physical } \\
\text { activity, comorbidities }\end{array}$ & 7 \\
\hline PRO.V.A. study & $\begin{array}{l}\text { Age, sex, body mass index, diabetes, hypertension, orthostatic hypotension, } \\
\text { cardiovascular diseases, fractures, chronic obstructive pulmonary disease, cancer, } \\
\text { educational level, smoking habits, monthly income, alcohol drinking, physical activity } \\
\text { level, activities of daily living preserved, geriatric depression scale score, mini-mental } \\
\text { state examination score, Geriatric Nutrition Risk Index, number of drugs, frailty }\end{array}$ & 21 \\
\hline
\end{tabular}


Supplementary Figure 1. PRISMA flow diagram of systematic review of literature
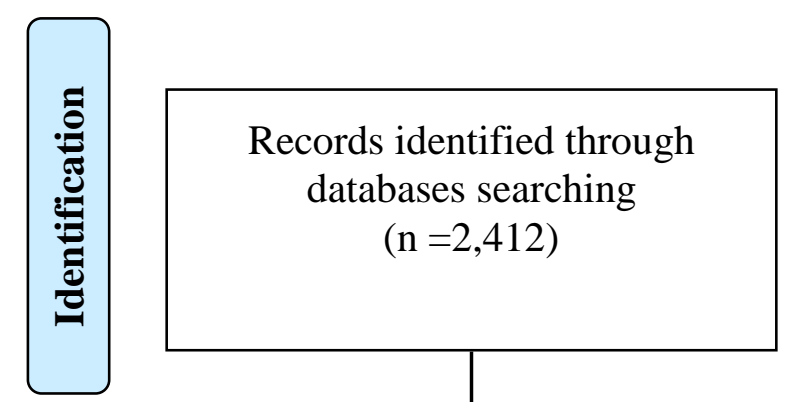

Additional records identified through manual search

$$
(n=2)
$$

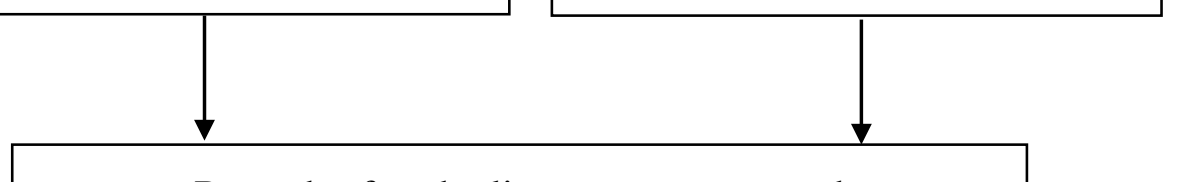

Records after duplicates were removed

(n =2,319)

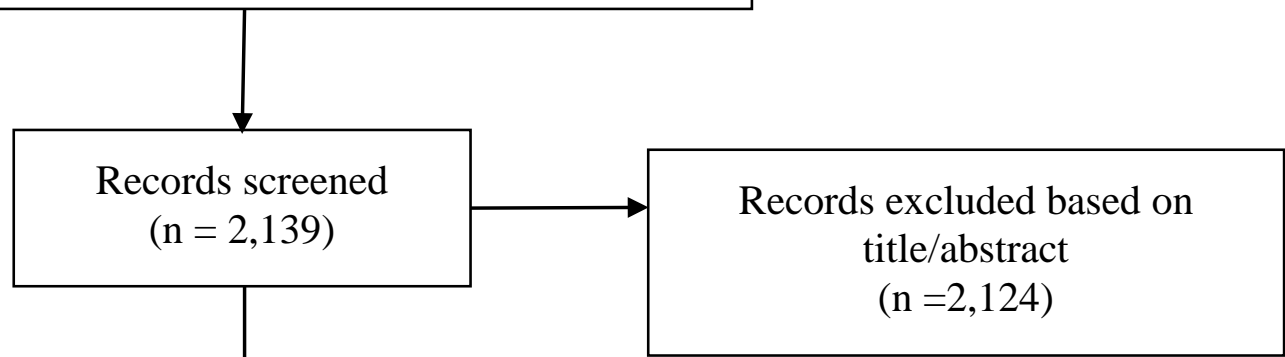

Full-text articles assessed for eligibility $(n=15)$ Full-text articles excluded $(\mathrm{n}=9)$ No control group $(n=6)$ Estimates other than HR $(n=2)$ Reviews $(n=1)$

Studies included in quantitative synthesis (meta-analysis)

$$
(n=6)
$$
and PRO.V.A. study 